\title{
Comparitive phytochemical Analysis and Resilience Pattern Exhibited by thyme and tea tree oil against Selected Poultry Isolates
}

\author{
Seema Nimbarte ${ }^{* 1}$, Archana Kulkarni ${ }^{2}$

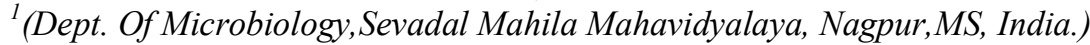 \\ ${ }^{2}$ (Dept. Of Microbiology, Dharampeth M.P. Deo Memorial science College, Nagpur,MS, India.)
}

\begin{abstract}
The volatile oils of Melaleuca alternifolia (tea tree) and Thymus vulgaris (thyme), of the family Myrtaceae and Lamiaceae respectively, were asessed for antibacterial activity against different avian pathogens isolated from infected chickens which involved Escherichia coli, Staphylococcus aureus, S.epidermidis, S. carnosus and Salmonella gallinarum. The antimicrobial activity of both the oils was assessed by using disc diffusion, minimum inhibitory concentration (MIC) as well as minimum bactericidal concentration (MBC) method. Thyme oil exhibited higher activity than tea tree oil against all the pathogens. Mean inhibition zones, MIC and MBC values of bacterial strains varied from 19 and $34 \mathrm{~mm}, 0.03 \%-0.15 \%$ to $0.07-0.3 \%$ respectively. GC-MS analysis of essential oil of thyme showed the presence of 13 components. The major components were carvacrol, thymol, terpinene-4-ol, $\alpha$-Terpinene, carvacrol methyl ether. Tea tree oil showed the presence of 16 components upon GC-MS analysis. The major compounds were Limonene, $\gamma-T e r p i n e n e, \alpha-$ Terpinene, Cineol and $\alpha$-Terpinolene. Since aromatic and medicinal plants produce a wide variety of volatile terpenes, hydrocarbons (aliphatic and cyclic) and their corresponding oxygenated isoprenoid derivatives and analogues, the bactericidal effect observed in this study may be attributed to these components. Therefore, these oils could be a source of pharmaceutical materials required for the preparation of new therapentic and antimicrobial agents.
\end{abstract}

Key words: Melaleuca alternifolia, Thymus vulgaris, avian pathogens, antimicrobial activity, MIC, MBC.

\section{Introduction}

Poultry not only plays an important role in narrowing the gap between the demand and supply of protein of animal origin but also provides an efficient means of income generation in small scale. The poultry industry has now recognized as an important sub sector of the agriculture [1]. India produces, approximately, 1,400 million chickens a year, which is close to 27 million a week, of which $95 \%$ is traded alive (Indian Poultry and its Future Prospects, Ministry of food processing industry). Hence the main objective of the broiler industry is the production of saleable chicken meat. Therefore it is important that the number of condemnations at the processing plant should be minimized and the meat yield be maximized and to produce a quality chicken meat from a live broiler. Typically, the main reason for condemnations is septicaemia, which refers to the presence of bacteria in the bloodstream of a chicken. One most important bacteria responsible for septicaemia is E. coli. S. aureus may also be one of the bacteria responsible for this. Fowl typhoid caused by Salmonella gallinarum is a septicaemic bacterial disease primarily of chickens and turkeys and is also responsible for high mortality and vertical transmission of the infection. Antimicrobial therapy is an important tool in reducing both the incidence and mortality associated with various avian pathogens. However, poultry isolates are frequently resistant to one or more antibiotics, especially if they have been widely used in poultry industry over a long period (e.g. tetracyclines)[2,3]. Antimicrobial resistance in zoonotic enteropathogens including Salmonella, Escherichia coli (E.coli), and Enterococci in food animals is of special concern to human health because these bacteria are likely to transfer from the food chain to humans. [4]. In addition to the human health concerns, antimicrobial-resistant pathogens also pose a severe and costly animal health problem in that they may prolong illness and decrease productivity through higher morbidity and mortality. [5]. Hence there is a need to search for an alternative to these conventional antimicrobials.

The antimicrobial properties of essential oils are well recognized for many years $[6,7]$ and their preparations find applications as naturally occurring antimicrobial agents in pharmacology, pharmaceutical botany, phytopathology, medical and clinical microbiology, food preservation etc. Thus, the discovery of essential oil (EO) preparations that possess antimicrobial activities has thus been the objective of many research investigations leading to the screening of a variety of plant species that produce EO's as secondary metabolites. The objective of this study was to assess the main constituents of these two oils and to evaluate and compare their antimicrobial activities against poultry pathogens. 


\begin{abstract}
II. Material Methods
2.1 Collection, Isolation and Identification of Samples:

A total of $81 \%$ E.coli, 5\% S.aureus and S.epidemidis each, 1\% S.carnosus and 2\% Salmonella gallinarum samples from 105 birds of 2-6 weeks of age were collected based on clinical findings and pathogonomic lesions observed during detailed post mortem examination of poultry. Samples were collected form cases exhibiting perihepatitis, enteritis, airsacculitis and pericarditis, gangrenous dermatitis, necrotic spotted liver.

Isolation and identification of E. Coli were performed by standard bacteriological methods. Specimens were directly cultured on McConkey, EMB agar, xylose lysine deoxycholate agar and mannitol salt agar and the growth was identified by standard methods including Gram stain. 87 strains of E.coli, 5 strains of S.aureus, 5 strains of S.epidemidis, 1 strain of S.carnosus and 2 strains of Salmonella gallinarum were isolated from broiler chickens ( $2-6$ weeks of age), during March 2012 to August 2012 from different poultry farms in and around Nagpur.
\end{abstract}

\title{
2.2 Gas Chromatography and Mass Spectroscopy (GC-MS) Studies
}

The GC-MS studies were performed using Shimadzu QP-2000 GC/MS instrument at 70eV (unless otherwise specified) equivalent to OV-1, fused silica capacity $-0.25 \mathrm{~mm} \mathrm{X} 50 \mathrm{M}$ with film thickness -0.25 micron. The entry on the GC- MS trace such as 100-6-10-250 means that the initial temperature was $100^{\circ} \mathrm{C}$ for 6 min and then heated at the rate of $10^{\circ} \mathrm{C}$ per minute to $250^{\circ} \mathrm{C}$. Carrier gas (helium) flow: $2 \mathrm{ml}$ per minute. Identification of GC-MS spectra is based on the direct comparison of Kovates index and mass.

\subsection{Antimicrobial Activity of Essential Oils}

Antimicrobial activity of $M$. alternifolia and Thymus vulgaris activity against the poultry pathogens was tested using the paper disc diffusion method [8]. For this, sterilized blank Whatman filter paper discs of size $6 \mathrm{~mm}$ were used. These discs were impregnated with essential oil (TTO and thyme separately) for 20 minutes and kept in slanted position so as to drain off excess oil. These discs were later weighed and amount of oil per disc was fixed at $15 \mathrm{mg}$. A lawn culture of test strain on Mueller-Hinton agar was exposed to the discs of oil. The discs were placed in the centre of the plate. All the plates were kept in refrigerator for a period of 30 minutes to facilitate diffusion and then incubated at $37^{\circ} \mathrm{C}$ for $24 \mathrm{hrs}$. After incubation, results were noted by measuring zone of growth inhibition in $\mathrm{mm}$ using zone reader and average values of three replicates were calculated for each isolate and recorded. Ampicillin $(30 \mu \mathrm{g})$, Nitrofurantoin $(300 \mu \mathrm{g})$, Nalidixic acid $(30 \mu \mathrm{g})$, Ofloxacin $(5 \mu \mathrm{g})$, Norfloxacin $(10 \mu)$, Ciprofloxacin $(30 \mu \mathrm{g})$, Tetracycline $(30 \mu \mathrm{g})$, Oxytetracycline $(30 \mu \mathrm{g})$, Chloramphenicol $(30 \mu \mathrm{g})$, Amikacin $(30 \mu \mathrm{g})$, Streptomycin $(10 \mu \mathrm{g})$, Colistin $(10 \mu \mathrm{g}), \quad$ Gentamycin $(10 \mu \mathrm{g})$, Ceftazidime $(30 \mu \mathrm{g})$, Cephalexin $(30 \mu \mathrm{g})$. were used as positive reference standards (HIMEDIA, India).

\subsection{Determination of MIC and MBC}

Minimum inhibitory concentrations (MICs) of both the oils were determined by broth microdilution method according to National Committee for Clinical Laboratory Standards (NCCLS) methods with minor modifications. Briefly, doubling dilutions of components, with final concentrations ranging from $2.5 \%$ to $0.00488 \%(\mathrm{v} / \mathrm{v})$ were prepared in 96 -well microtitre plates. $5 \%$ Tween 80 emulsifier base was prepared in MHB. In this $5 \%$ solution of essential oil was prepared. To prepare bacterial inoculums one or two morphologically similar colonies were selected and aliquot was transferred to a test tube containing nutrient broth and incubated at $37^{\circ} \mathrm{C}$ for $4 \mathrm{hrs}$. The density of the suspension was standardized by McFarland 0.5 standard.

Aliquots of broth culture from MIC test plates were subcultured on the surface of solid nutrient agar plates by streaking. The plates were incubated at $37^{\circ} \mathrm{C}$ for $24 \mathrm{hrs}$ and $\mathrm{MBC}$ 's were recorded after $24 \mathrm{hrs}$. Plates that did not show growth were considered to be the MBC for the oil used.

\section{1: GC-MS analysis of essential oils}

\section{Result And Discussion}

Aroma chemicals and phenolic compounds identified in the thyme oil, based on mass spectra were Terpinene-4-ol (32.7\%), Carvacrol (21.1\%), Thymol (18\%), Carvacrol methyl ether $(9.7 \%), \alpha$-Terpinene (7.4\%), $\alpha$-pinene (3.5\%), and p-cymene (1.0\%), which was also reported by others [9]. The identification of different compounds is based on the direct comparison of Kovates index and mass sepectra. The antimicrobial properties of thyme oil are due to its main components: Thymol, carvacrol [10]. Besides, there are several chemotypes for thyme, such as: Linalool, $\alpha$-terpineol, thymol. Carvacrol-cymene, Terpinene-4-ol, and 1, 8cineole, most of them are reported to show varying degree of antimicrobial activity[11].

GC-MS profile of the tea tree oil showed that 4-terpineol (48.7\%), followed by Terpinene (12.7\%), $\gamma$-Terpinene (10.4\%), Cineol (7.3\%), p-cymene (4.1\%), a-pinene (2.5\%), $\alpha$-Terpineol (2.0\%), $\alpha$-Terpinolene (1.0\%), $\alpha$ - p- 
cyeme-8-ol $(0.4 \%)$. The identification is based on the direct comparison of Kovates index and mass sepectra. It has been reported that various components of tea tree oil are active against bacteria and yeast [12].

Thus the antimicrobial activity of essential oils is assigned to a number of small terpenoids and phenolic compounds, which also in pure form demonstrate high antibacterial activity [13].

\section{2: Antimicrobial activity of tea tree and thyme oil}

Our results revealed that the two essential oils showed antibacterial activity with varying magnitudes. The anti-bacterial activity of two essential oils against five bacterial strains isolated from infected broilers is summarized in Table 1. The zone of inhibition (ZOI) above $11 \mathrm{~mm}$ in diameter was taken as positive result. All the tested organisms were sensitive to both of the essential oils. Thyme oil showed maximum activity against all the bacterial species tested followed by tea tree oil. In the present study, both the essential oils were found to be equally effective against both gram-positive and gram-negative organisms and the inhibition zones were found to be in the range of 19 to $34 \mathrm{~mm}$.

Minimum inhibitory concentration (MIC) for the oils (Fig 1)ranged from $0.019 \% \%$ to $0.15 \%$. This study revealed that thyme oil showed maximum activity with MIC values ranging from $0.019 \%$ to $0.03 \%$ followed by Tea tree oil with MIC values ranging from $0.07 \%$ to $0.15 \%$ against all the tested strains. Our results corroborates with those of Pooja Bharti et al., 2012 [14].

The MBC values (Fig 2) were found in the range of $0.03 \%$ to $0.07 \%$ for thyme oil followed by $0.3 \%$ for tea tree oil against the tested pathogens. It has been documented that Gram-positive bacteria are more susceptible to essential oils than Gram-negative bacteria. $[15,16]$. Our results corroborates with these findings. The reason is that the outer membrane of the gram-negative organisms containing lipopolysaccharide protects the bacteria from EOs' disruption.In addition, the geographical origin and harvesting period affect the EOs in composition between batches, which further cause variability in the degree of susceptibility of gram-negative and gram-positive bacteria [17].

Table 1: Zone of inhibition recorded with tea tree oil and thyme oil against different poultry pathogens

\begin{tabular}{|l|l|l|}
\hline Pathogen & ZOI of Thyme oil $(\mathrm{mm})$ & ZOI of Tea tree oil $(\mathrm{mm})$ \\
\hline E.coli & $28 \pm 2$ & $22 \pm 3$ \\
\hline S.aureus & $30 \pm 2$ & $23 \pm 2$ \\
\hline S.epidermidis & $31 \pm 2$ & $23 \pm 3$ \\
\hline S.carnosus & $31 \pm 2$ & $23 \pm 3$ \\
\hline Salmonella gallinarum & $33 \pm 1$ & $25 \pm 1$ \\
\hline
\end{tabular}

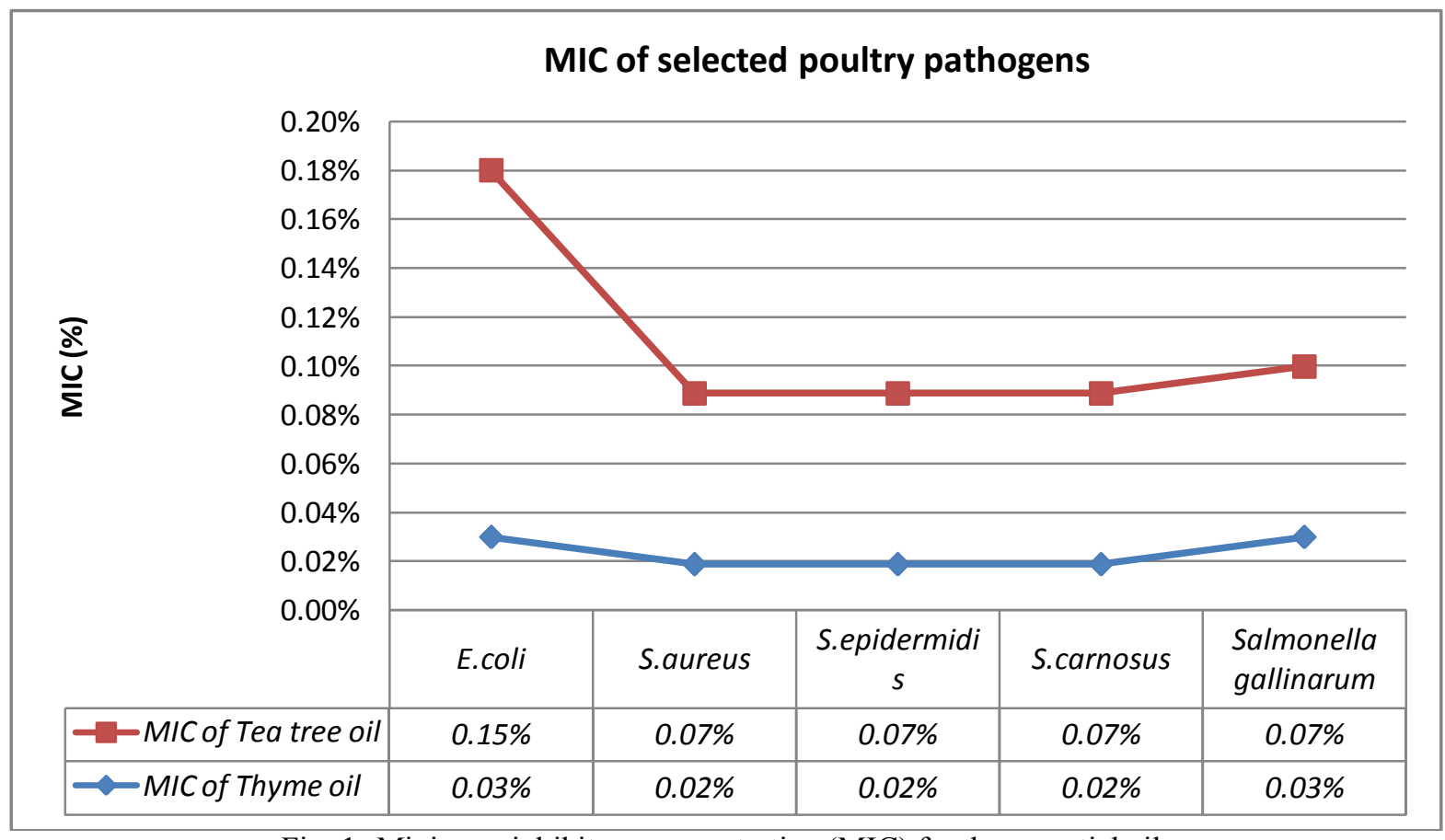

Fig: 1- Minimum inhibitory concentration (MIC) for the essential oils 


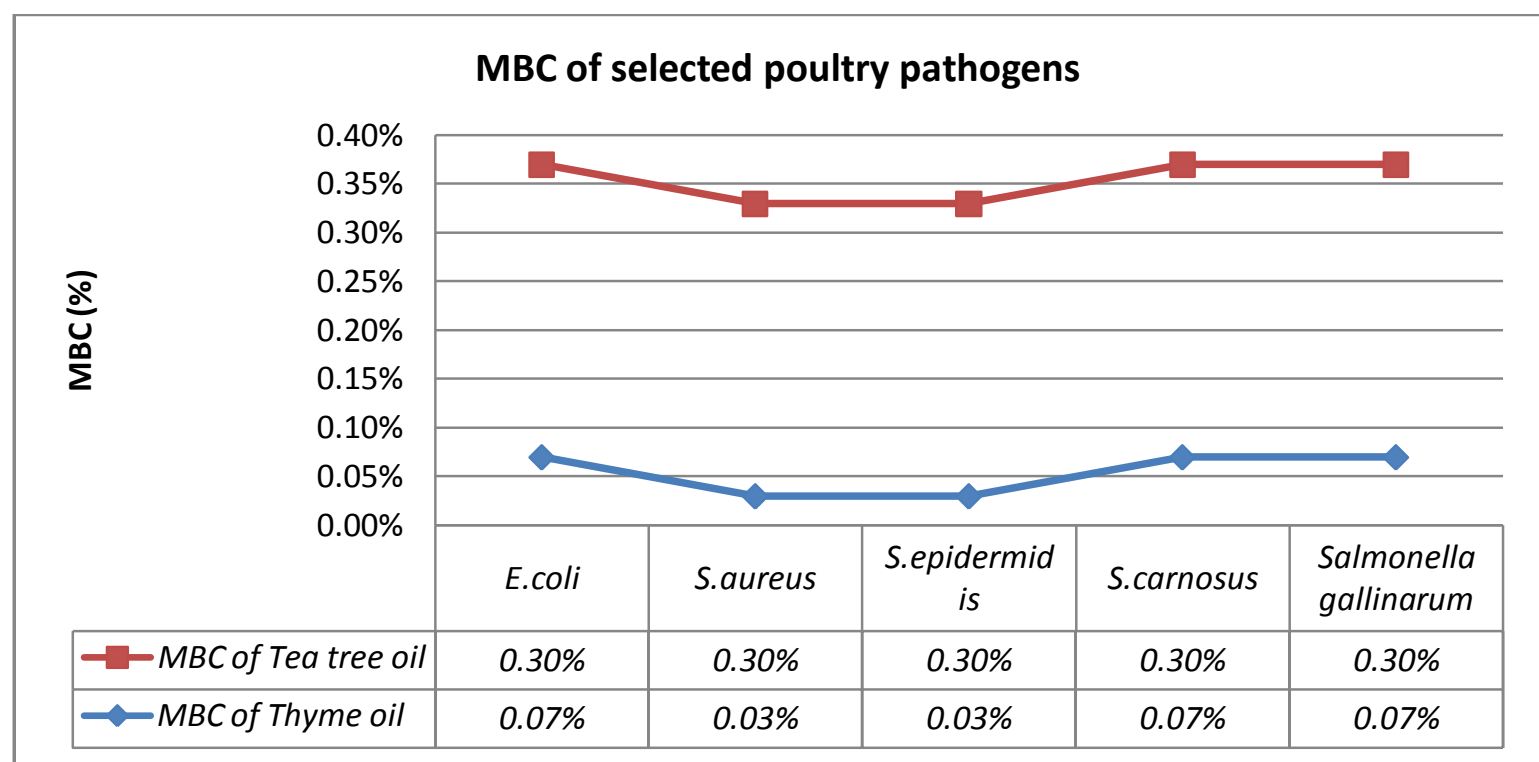

Fig: 2- Minimum bactericidal concentration (MBC) for the essential oils

The above results thus reveal that essential oils are potential sources of novel antimicrobial compounds especially against poultry pathogens. An important characteristic of essential oils and their components is their hydrophobicity, which enable them to partition the lipids of the bacterial cell membrane and mitochondria, disturbing the cell structures and rendering them more permeable $[18,19]$. Extensive leakage from bacterial cells or the exit of critical molecules and ions will lead to death [20]. Some studies have shown that some of the major components in EOs are not necessarily the most important to the antimicrobial activity [21]. Additionally, the unfractionated EOs sometimes have stronger antimicrobial activity than isolated major components [22,23]. This indicates that minor, or even trace elements may be critical to the antimicrobial activity. It is possible that the complexity of an essential oil helps to enhance the antimicrobial activity because bacteria cannot gain tolerance very easily [17].

\section{Conclusion}

From this study it can be concluded that both the essential oils possessed potent antibacterial activity. Hence there is a need to verify in vivo effect. For this if the blend of these oils mixed in poultry feed is administered to these birds, would help to minimize complications arising through bacterial infections and may also help in improving the overall health of the birds. Further Additional in vivo studies and clinical trials would be needed to justify its efficacy.

\section{References}

[1] Mushtaq, A.M., 1994. Poultry production. In: Animal Husbandry. National Book Foundation, Islamabad, pp. $292-334$.

[2] Allan, B.J., Van den Hurk, J.V. and Potter, A. A. 1993. Characterization of Escherichia coli isolated from cases of avian colibacillosis. Can. J. Vet. Res., 57: 146-151.

[3] Blanco, J.E., Blanco, M., Mora, A. and Blanco, J. 1997. Prevalence of bacterial resistance to quinolones and other antimicrobials among avian Escherichia coli strains isolated from septicemic and healthy chickens in Spain. J. Clin. Microbiol., 35: $2184-2185$.

[4] Endtz, H. P., G. H. Rujis, and B. Van Klingeren. 1991. Quinolon resistance in Campylobacter isolated from man and poultry following the introduction of fluroquinolones in veterinary medicine. J. Antimicorb. Chemother. 27: 199-208.

[5] Xu, S. 2001. Actions China needs to take in response to the emergence of antimicrobial resistance. Chinese J. Vet. Drugs 35:39-41.

[6] Hammer, K.A., Carson, C.F. and Riley, T.V. 1999. Influence of organic matter, cations and surfactants on the antimicrobial activity of Melaleuca alternifolia (tea tree) oil in vitro. J. Appl. Microbiol., 86(3):446-52.

[7] Cosentino, S., Tuberoso, C.I.G., Pisano, B., Satta, M., Mascia, V., Arzedi, E. and Palmas, F. 1999. In-vitro antimicrobial activity and chemical composition of Sardinian Thymus essential oils. Letters in Applied Microbiology 29, 130-135.

[8] Bauer. A. W., Kirby. M. M., Sharis. J. L, and Turck. M. 1966. Antibiotic susceptibility testing by a standard single disk method, Am. J. Clin. Pathol. 45, 493-496

[9] Penalver P, Huerta B, Borge C, Astorga R, Romero R, Perea A. 2005. Antimicrobial activity of fi ve essential oils against origin strains of the Enterobacteriaceae family. APMIS, 113: 1-6.

[10] Munouz, F., Plantas medicinales Y aromaticas. Estudio, Cultivoy procesado., 1993. 365p.mundi Prensa, Madrid.

[11] Kaloustain, B.M. and Reynolds, R. J. 1984. P \& F, 9:23-31.

[12] Carson. C. F and Riley. T. V., Antimicrobial activity of the major components of the essential oil of Melaleuca alternifolia, Journal of Applied Bacteriology, 78, 1995, 264-269.

[13] Conner. D.,E. 1993. Naturally occurring compounds. In: Antimicrobials in Foods Davidson P, Branen AL, Marcel Dekker publishing company New York.

[14] Pooja Bharti, Sheema Bai, Leena Seasotiya, Anupma Malik and Sunita Dalal. 2012. "Antibacterial activity and Chemical Composition of Essential Oils of Ten Aromatic Plants against selected Bacteria” Int. J. Drug Dev. \& Res., October-December; 4(4): 342-351. 
[15] Outtara B., Simard R. E., Holley R. A., Piettte G. J. P. and Begin A. 1997. Antimicrobial activity of se lected fatty acids and essential oils against six meat spoilage organisms. Int. J. Food Microbiol. 37, 155D- 162.

[16] Mangena T. and Muyima N. Y. O. 1999. Comparative evaluation of the antimicrobial activities of essential oils of Artemisia afra, Pteronia incana and Rosmarinus officinalis on selected bacteria and yeast strains. Lett.Appl. Microbiol. 28, 291D-296.

[17] Burt, S. 2004. Essential oils: their antibacterial properties and potential applications in foods - a review. International Journal of Food Microbiology 94, 223-253.

[18] Mitscher LA, Drake S, Gollapudi SR, Okwute SK. 1987. A modern look at folkloric use of anti-infective agents. J Nat Prod; 50:1025-1040.

[19] Knobloch K, Weigand H, Weis N, Schwarm HM, Vigenschow H: Action of terpenoids on energy metabolism. In Progress in Essential Oil Research: 1986 16th International Symposium on Essential Oils. Edited by Brunke EJ. De Gruyter, Berlin; 429- 445. 13

[20] Sikkema J, De Bont JAM, Poolman B: 1994. Interactions of cyclic hydrocarbons with biological membranes. $J$ Biol Chem; 269:8022-8028.

[21] Chao, S.C., Young, D.G., Oberg, C.J. 2000. Screening for inhibitory activity of essential oils on selected bacteria, fungi and viruses. Journal of Essential Oil Research 12,639-649.

[22] Mourey, A., Canillac, N. 2002. Anti-Listeria monocytogenes activity of essential oils components of conifers. Food Control 13, 289-292.

[23] De Giusti, M., Aurigemma, C., Marinelli, L., Tufi, D., De Medici, D., Di Pasquale, S., De Vito, C., Boccia, A. 2010. The evaluation of the microbial safety of fresh ready to-eat vegetables produced by different technologies in Italy. Journal of Applied Microbiology 109, 996-1006. 